DOI: $\underline{\text { https://doi.org/10.24867/14BE25Milosavljevic }}$

\title{
KVALITET ELEKTRIČNE ENERGIJE INDUSTRIJSKOG POTROŠAČA NA NAFTNOJ BUŠOTINI
}

\section{POWER QUALITY OF INDUSTRIAL CONSUMER ON OIL RIG}

\author{
Slobodan Milosavljević, Vladimir Popović, Fakultet tehničkih nauka, Novi Sad
}

\section{Oblast - ELEKTROTEHNIKA I RAČUNARSTVO}

Kratak sadržaj - U ovom radu je prikazan kvalitet električne energije industrijskog potrošača na naftnoj bušotini. Polazi se od teorijskog opisa kvaliteta električne energije sa svim ključnim parametrima koji su bitni za njegov opis. Zatim se definiše merna metoda kao $i$ instrumentacija za snimanje $i$ monitoring kvaliteta. $\mathrm{Na}$ kraju, daje se prikaz eksperimentalnih rezultata merenja $i$ izvode se zaključci o kvalitetu isporuke električne energije.

Ključne reči: Kvalitet električne energije, Harmonijsko izobličenje, Industrijski potrošač

Abstract - This paper presents the power quality of
industrial consumer on oil rig. First, theoretical
background regarding the power quality in general is
given, with all the parameters of relevance. Then, the
measuring method is defined for power quality analysis.
At the end, experimental results were given regarding the
power quality of oil rig industrial consumer and the
conclusion is presented accordingly.

Keywords: Power quality, Harmonic distortion, Industrial consumer

\section{UVOD}

Predmet istraživanja ovog master rada je kvalitet električne energije industrijskog potrošača. Kvalitet električne energije je jedan od važnih parametara, koji određuje cenu i atraktivnost proizvoda ili usluge i dobija na posebnom značaju krajem 20-og i početkom 21-og veka. Kao aspekat elektroenergetskog sistema kvalitet napajanja $\mathrm{i}$ isporuke ranije nije bio dovoljno istaknut kao odvojen, već su se pitanja kvaliteta pojavljivala i rešavala kao posebni problemi pouzdanosti, stabilnosti, naponske regulacije i servisiranja. Danas, kada se govori o kvalitetu uopšte, misli se na četiri aspekta: upotrebnom kvalitetu, ekološkom kvalitetu, komercijalnom kvalitetu i tehničkom kvalitetu električne energije. Kvalitet električne energije podrazumeva izvore, posledice i metode kontrole poremećaja, koje se prenose preko elektroenergetskog sistema i utiču na kvalitet napajanja krajnjih potrošača [1].

U ovom radu govori se pretežno i tehničkom kvalitetu energije $i$ to na konkretnom primeru industrijskog potrošača na naftnoj bušotini.

\section{NAPOMENA:}

Ovaj rad proistekao je iz master rada čiji mentor je bio dr Vladimor Popović.

\section{UTICAJ KVALITETA ELEKTRIČNE ENERGIJE NA POTROŠAČE U EES}

U elektroenergetskom sistemu (EES) se sa vremenom rapidno promenila struktura potrošača u korist povećanog prisustva naponskih osetljivih elektronskih potrošača primenjenih u industriji i domaćinstvima. Varijacije napona dovode do nepravilnog rada ovakvih uređaja ili kvarova, što rezultuje štetama kod potrošača i neoptimalnom toku snaga u EES. Zbog ovakvih čestih pojava, korisnici električne energije očekuju sve veći kvalitet napona koji podrazumeva odstupanja napona u precizno definisanim granicama definisanim tehničkim standardima. Da bi se kvalitet električne energije održao na potrebnom nivou, pred proizvođače i projektante uređaja energetske elektronike postavljen je čitav niz standarda i preporuka iz oblasti kvaliteta električne energije [2].

Neki od problema koje stvaraju harmonici struje su:

- izobličenje talasnog oblika napona na distributivnoj mreži (problem kompatibilnosti),

- pregrevanje nultog provodnika,

- pregrevanje transformatora,

- pregrevanje i nepravilan rad električnih motora,

- ugroženost funkcionalnosti relejne zaštite,

- ugroženost rada elektronske opreme,

- uticaj na rad statičkih energetskih pretvarača,

- uticaj na telekomunikacione veze,

- naprezanje kondenzatorskih baterija za kompenzaciju reaktivne energije...

\section{KVALITET ELEKTRIČNE ENERGIJE}

Kvalitet isporučene električne energije, sa aspekta elektrodistribucije, podrazumeva kvalitet napona na sabirnici na koju se priključuju razni potrošači - tačka zajedničkog priključenja (PCC - point of common coupling). On podrazumeva da se osnovne karakteristike napona efektivna vrednost, frekvencija, simetričnost i talasni oblik (sinusoidalnost) drže u zadatim okvirima, odnosno na nominalnim vrednostima u ustaljenom stanju elektroenergetskog sistema. U slučaju pojedinačne ili učestale degradacije kvaliteta električne energije, potrošači će iskusiti neke od ranije pomenutih negativnih efekata. Pojava takvih problema će biti indikacija da nešto sa napajanjem nije u redu, mada, u opštem slučaju, uzrok ne mora biti u nekvalitetnom naponu na sabirnici. Osnovni parametri napona, kao osnovna grupa činilaca kvaliteta su: varijacija efektivne vrednosti napona, varijacija frekvencije i pojava nesimetrije u mreži 
Uzroci pojave deformacija napona mogu biti različiti i vezani su za razne aspekte rada elektroenergetskog sistema i uticaja okoline na njega. Mogu se razlikovati sledeći uzroci:

- Rad nelineranih potrošača (energetski elektronski pretvarači, indukcione i elektrolučne peći, zasićene električne mašine $i d r$.). Usled prekidačke prirode rada ili nelinearne karakteristike oni konzumiraju nesinusoidalnu struju i dovode do pojave deformacije mrežnog napona (stvaranja viših harmonika, flikera, rupa i ureza u naponu $i$ šuma).

- Normalne operacije u mreži (neophodne prekidačke manipulacije, priključenja i remont opreme), koje mogu izazvati deformacije tranzijentne prirode $\mathrm{i}$ deformacije u prelaznim režimima.

- Dejstvo prirodnih faktora (atmosferske nepogode, udari munje u vazdušne vodove, grane drveća, sitne životinje, ptice $i d r$.), koji izazivaju zemljospojeve i međufazne kratke spojeve, prenapone, podnapone, propade napona i sl.

- Rad opreme i lokalnog energetskog sistema (startovanje velikih elektromotornih pogona, nagle dinamičke promene opterećenja ili rada pogona, nelinearnosti u električnim mašinama, fluorescentno osvetljenje itd.), koji izazivaju varijacije napona, propade napona i sl.

Tabela 1. Indikatori kvaliteta električne energije

\begin{tabular}{|c|c|c|}
\hline Indikator & Definicija & Glavna primena \\
\hline $\begin{array}{c}\text { Ukupna } \\
\text { harmonijska } \\
\text { distrozija } \\
\text { (THDU, THDI) }\end{array}$ & $\sqrt{\frac{\sum_{h=2}^{\infty} I_{h}^{2}}{U_{1}^{2}}}, \sqrt{\frac{\sum_{h=2}^{\infty} I_{h}^{2}}{I_{1}^{2}}}$ & $\begin{array}{l}\text { Opisivanje nivoa } \\
\text { viših harmonika, } \\
\text { standardi }\end{array}$ \\
\hline $\begin{array}{c}\text { Individualna } \\
\text { harmonijska } \\
\text { distrozija (HD } \\
\text { Uh, HD Ih) }\end{array}$ & $\frac{U_{h}}{U_{1}}, \frac{I_{h}}{I_{1}}$ & $\begin{array}{l}\text { Opisivanje nivoa } \\
\text { viših harmonika, } \\
\text { standardi }\end{array}$ \\
\hline $\begin{array}{c}\text { Faktor snage }(\mathrm{PF}, \\
\lambda)\end{array}$ & $P_{t o t} /\left|U_{e f f}\right| \cdot\left|I_{e f f}\right|$ & $\begin{array}{c}\text { Naplata reaktivne } \\
\text { i harmonijske } \\
\text { snage } \\
\text { (mogućnost) }\end{array}$ \\
\hline Fliker faktor & $\Delta U /|U|$ & $\begin{array}{c}\text { Opis uticaja } \\
\text { nelinearnih } \\
\text { potrošača preko } \\
\text { neregularnog rada } \\
\text { žarulja }\end{array}$ \\
\hline $\begin{array}{c}\text { Faktor varijacije } \\
\text { napona (efektivna } \\
\text { vrednost } i \\
\text { trajanje) }\end{array}$ & $\begin{array}{c}U_{e f f} / U_{n o m} \cdot 100[\%] \\
\Delta t\end{array}$ & $\begin{array}{c}\text { Varijacije napona, } \\
\text { propadi ili } \\
\text { poskoci napona, } \\
\text { podnaponi, } \\
\text { prenaponi, } \\
\text { beznaponske } \\
\text { pauze }\end{array}$ \\
\hline $\begin{array}{c}\text { Faktor } \\
\text { nesimetrije }\end{array}$ & $\left|U_{-}\right| /\left|U_{+}\right|$ & $\begin{array}{l}\text { Nesimetrija } \\
\text { trofaznih mreža }\end{array}$ \\
\hline $\begin{array}{c}\text { Krest (Crest eng.) } \\
\text { faktor }\end{array}$ & $U_{\text {peak }} / U_{e f f}$ & $\begin{array}{l}\text { Vek trajanja } \\
\text { dielektrika }\end{array}$ \\
\hline
\end{tabular}

U Tabeli 1. prikazani su indikatori kvaliteta električne energije, dok su u Tabeli 2. date karakteristike nelinearnih potrošača koji unose harmonike u mrežu!

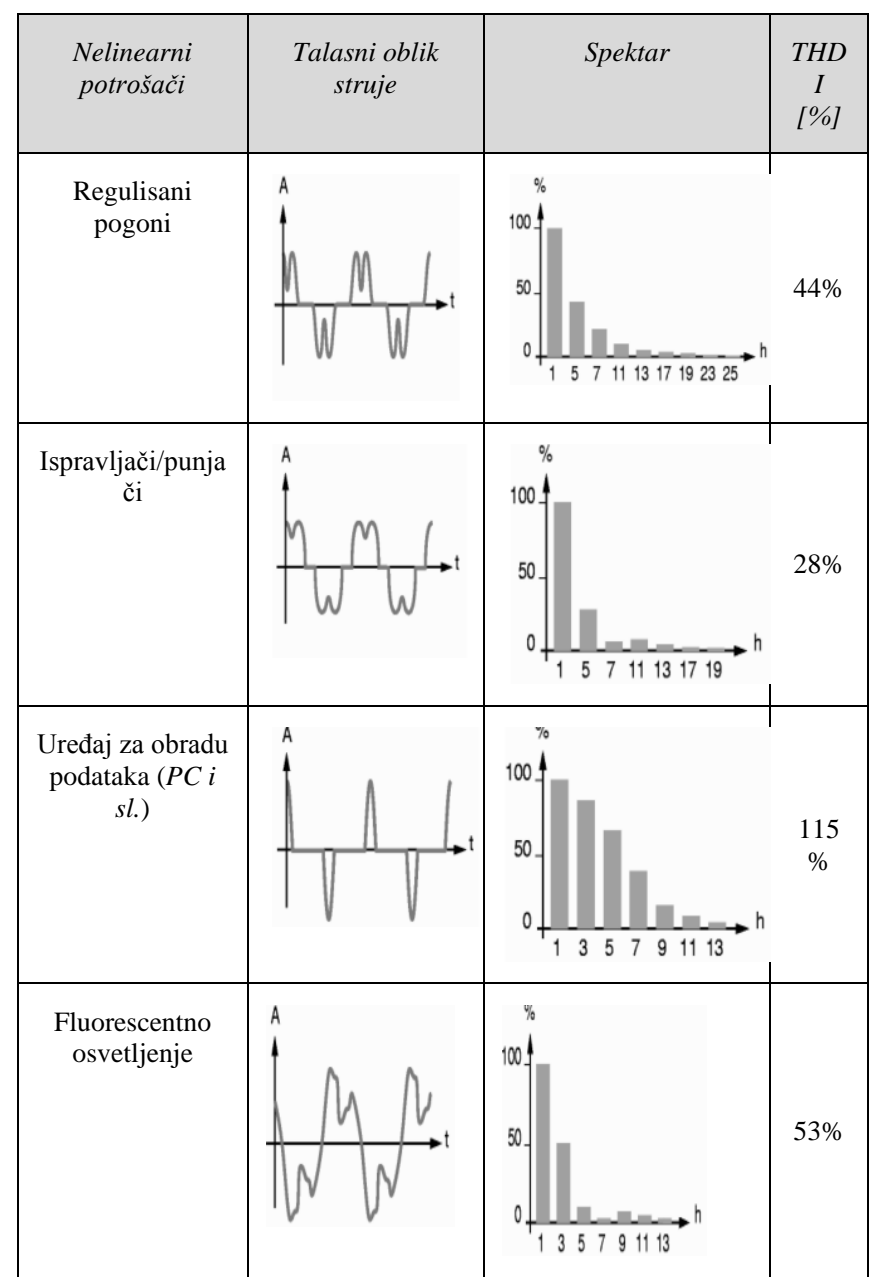

Tabela 2 - Karakteristike određenih izvora harmonika

\section{FURIJEOVI REDOVI I TRANSFORMACIJA}

Furijeova analiza je oblast u matematici koja je primenljiva u drugim naučnim granama (obrada signala, električna kola, itd.), i bavi se funkcijama koje se mogu predstaviti kao beskonačne sume trigonometrijskih funkcija, i na taj način se aproksimirati. Furijeove transformacije se mogu primeniti na neperiodične funkcije.

Furijeova transformacija se primenjuje na neperiodične funkcije, pa ćemo primeniti Furijeov red na neperiodičnu funkciju koju ćemo aproksimirati na periodičnu, ali takvu da njen period teži beskonačnosti, [4].

Furijeov obrazac:

$$
\begin{gathered}
f(x)=f(x+T) \\
f(x)=\frac{a_{0}}{2}+\sum_{n=1}^{\infty}\left(a_{n} \cos n x+b_{n} \sin n x\right), x \in R \\
a_{n}=A_{n} \cdot \cos \varphi_{n}, b_{n}=A_{n} \cdot \sin \varphi_{n} ; \\
A_{n}=\sqrt{a_{n}^{2}+b_{n}^{2}}, \varphi_{n}=\operatorname{arctg} \frac{b_{n}}{a_{n}} ;
\end{gathered}
$$

Prikazani matematički alat je implementiran u okviru uređaja za merenje kvaliteta električne energije, tzv. Analizatori mreže (eng. Power analyser).

\section{OPIS UREĐAJA ZA MERENJE KVALITETA}

Višenamenski merač Siemens SENTRON PAC3200 je instrument koji omogućava vizualizaciju najrelevantnijih 
mrežnih parametara. Pored merenja vrednosti električnih veličina, kao što su napon i struja,omogućava i merenje prividne, aktivne, reaktivne snage, energije, nazivne vrednosti, frekvencije, faktora snage i simetriju i dr., [3].

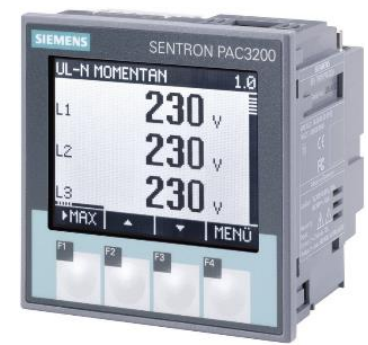

Slika 1. Siemens SENTRON PAC3200, analizator mreže [3]

\subsection{Tipovi povezivanja uređaja sentron pac3200}

\begin{tabular}{|l|l|}
\hline $\begin{array}{l}\text { Kraća } \\
\text { oznaka }\end{array}$ & Tip povezivanja \\
\hline 3P4W & $\begin{array}{l}\text { 3 faze, 4 provodnika, neuravnoteženo } \\
\text { opterećenje }\end{array}$ \\
\hline 3P3W & $\begin{array}{l}\text { 3 faze, } 3 \text { provodnika, neuravnoteženo } \\
\text { opterećenje }\end{array}$ \\
\hline 3P4WB & $\begin{array}{l}\text { 3 faze, 4 provodnika, uravnozeženo } \\
\text { opterećenje }\end{array}$ \\
\hline 3P3WB & $\begin{array}{l}\text { 3 faze, } 3 \text { provodnika, uravnoteženo } \\
\text { opterećenje }\end{array}$ \\
\hline 1P2W & 1 faza, 2 provodnika, AC \\
\hline
\end{tabular}

Tabela 3 - Mogući načini povezivanja SENTRON PAC3200 i odgovarajuće oznake

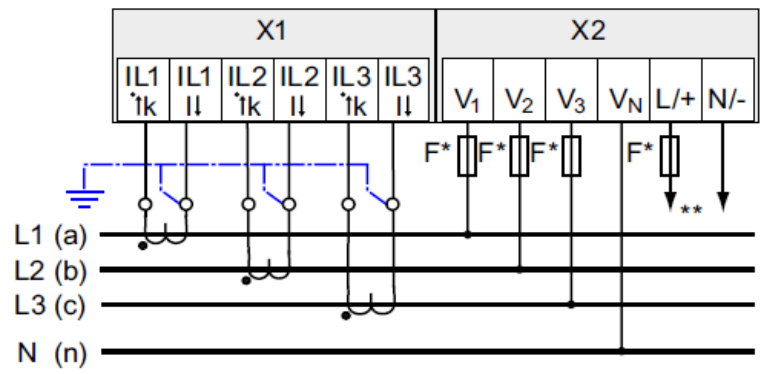

Slika 2 - Trofazno merenje, 4 provodnika, neuravnoteženo opterećenje, bez naponskih transformatora, sa tri strujna transformatora $(3 \mathrm{P} 4 \mathrm{~W})$

Primer trofaznog merenja je dat na Slici 2., gde postoje 4 provodnika za napajanje neuravnoteženog opterećenja, bez naponskih transformatora, sa tri strujna transformatora (poluindirektna metoda $-3 P 4 W$ ). Ovakva sprega je iskorišćena $u$ svrhe merenja kvaliteta električne energije industrijskog potrošača koji se razmatra u ovom radu.

\section{EKSPERIMENTALNI REZULTATI}

Rezultati i slike koji su prikazani u ovom poglavlju su snimljeni na naftnoj bušotini $u$ Turiji. Merenje na bušotinama se može vršiti u trafostanici, u ćeliji koja je predviđena za sopstvenu potrošnju ili u ćeliji koja je predviđena za naftne pumpe (koje možemo videti na mnogim mestima širom Vojvodine) gde postoji efektniji prikaz procesa napajanja naftne pumpe, njene potrošnje, izobličenja napona i struje, promene opterećenja, uticaja na mrežu itd.

Pored samog pokretanja naftne pumpe ista sadrži i grejače koji se nalaze pri dnu cevi kako bi se nafta zagrejala ukoliko je jako gusta da bi se olakšalo njeno izvlačenje. Ti grejači su napojeni preko istog voda kao i elektromotor koji pokreće naftnu pumpu. Ukoliko se u toku merenja aktiviraju grejači, njihov uticaj (ukoliko ga ima) na potrošnju, izobličenje i sve prethodno navedene stavke se mogu ispratiti na dijagramima koji se prate preko odgovarajućeg uređaja za merenje.

U ovom slučaju je korišćen Siemens SENTRON PAC3200 uređaj. Dijagrami i rezultati koji su u daljem tekstu prikazani su mereni u periodu od 20 minuta.

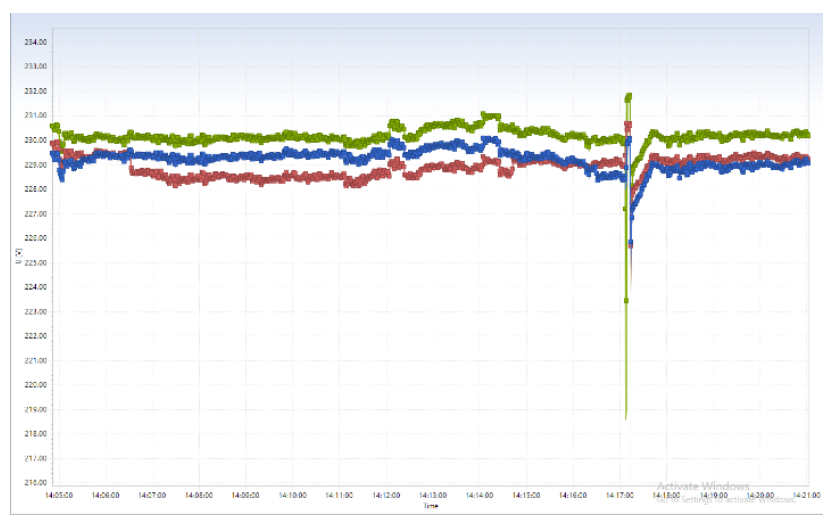

Slika 3. Fazni naponi U1, U2 i U3 industrijskog potrošača

Tabela 4 - Procentualno odstupanje (varijacije) tri faze napona industrijskog potrošača naftne bušotine

\begin{tabular}{|c|c|c|c|}
\hline \multirow{7}{*}{} & $\mathrm{U} 1$ & $\mathrm{U} 2$ & $\mathrm{U} 3$ \\
\cline { 2 - 4 } & 229.464 & 229.879 & 230.593 \\
\cline { 2 - 4 } & 229.377 & 229.841 & 230.553 \\
\cline { 2 - 4 } & 229.34 & 229.809 & 230.528 \\
\cline { 2 - 4 } & 229.206 & 229.677 & 230.419 \\
\cline { 2 - 4 } & 229.439 & 229.9 & 230.603 \\
\cline { 2 - 4 } & 229.461 & 229.943 & 230.637 \\
\cline { 2 - 4 } & 229.418 & 229.902 & 230.585 \\
\cline { 2 - 4 } & 229.434 & 229.904 & 230.602 \\
\cline { 2 - 4 } & 229.197 & 229.645 & 230.371 \\
\cline { 2 - 4 } & 228.763 & 229.234 & 229.953 \\
\hline $\begin{array}{c}\text { Srednja vrednost } \\
(V)\end{array}$ & 229.3099 & 229.7734 & 230.4844 \\
\hline $\begin{array}{c}\text { Procentualno } \\
\text { odstupanje (\%) }\end{array}$ & 0.300043 & 0.098522 & -0.21061 \\
\hline
\end{tabular}

Posmatrani potrošač je industrijski i spada u klasu 3 po standardu IEC 61000-2-4. Za ovaj potrošač, se po tom standardu gledaju pre svega:

- Varijacija napona u odnosu na nominalni $\Delta \boldsymbol{U}_{\text {eff }} / \boldsymbol{U}_{\text {nom }}$

- Propad napona $\boldsymbol{U}_{\text {eff }} / \boldsymbol{U}_{\text {nom }} \cdot \mathbf{1 0 0 [ \% ]}$

- Harmonici napona THDU [\%]

- Odstupanje frekvencije $\Delta \boldsymbol{f} / \boldsymbol{f}_{\text {nom }}$

Na Slici 3. prikazani fazni naponi U1, U2, U3. U Tabeli 4. su prikazane vrednosti napona u toku merenja. Na osnovu standarda IEC 61000-2-4 varijacije napona u odnosu na nominalni napon treba da budu u opsegu od $+10 \%$ do $15 \%$.

Na osnovu Tabele 4. se može zaključiti da je standard IEC 61000-2-4 zadovoljen, gde su varijacije napona sve tri faze manje od $1 \%$. 


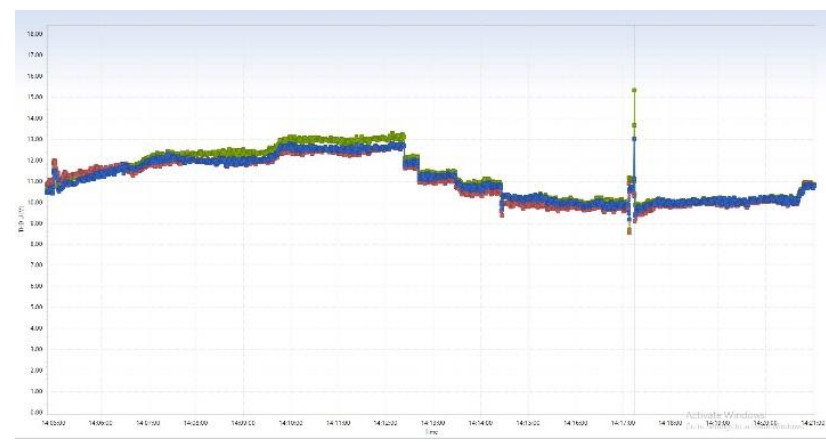

Slika 4. Totalno harmonijsko izobličenje napona U1, U2, U3

Tabela 5. Procentualne vrednosti totalnog harmonijskog izobličenja industrijskog potrošača naftne bušotine

\begin{tabular}{|c|c|c|c|}
\hline \multirow{5}{*}{} & THDU1 & THDU2 & THDU3 \\
\cline { 2 - 4 } & 10.437 & 10.815 & 10.591 \\
\cline { 2 - 4 } & 10.453 & 10.847 & 10.634 \\
\cline { 2 - 4 } & 10.508 & 10.907 & 10.711 \\
\cline { 2 - 4 } & 10.628 & 11.036 & 10.835 \\
\cline { 2 - 4 } & 10.611 & 11.023 & 10.812 \\
\cline { 2 - 4 } & 10.618 & 10.994 & 10.801 \\
\cline { 2 - 4 } & 10.457 & 10.864 & 10.676 \\
\cline { 2 - 4 } & 10.419 & 10.84 & 10.636 \\
\cline { 2 - 4 } & 10.725 & 11.136 & 10.895 \\
\cline { 2 - 4 } & 11.489 & 11.937 & 11.621 \\
\hline Srednja vrednost (V) & 10.6345 & 11.0399 & 10.8212 \\
\hline $\begin{array}{c}\text { Procentualna vrednost } \\
\text { (\%) }\end{array}$ & 4.623696 & 4.799957 & 4.70487 \\
\hline
\end{tabular}

Na Slici 4. dat je dijagramski prikaz Totalnog Harmonijskog Izobličenja faznih napona. U Tabeli 5. prikazane su vrednosti u voltima u toku merenja. Na osnovu standarda IEC 61000-2-4, totalno harmonijsko izobličenje THDU treba maksimalno da bude $10 \%$. Na osnovu Tabele 5. se može zaključiti da je ovaj standard zadovoljen jer se THDU kreće u opsegu oko 4-5\%.

Na Slici 5. prikazan je dijagram totalnog harmonijskog izobličenja struje u vremenu. U Tabeli 6 . date su procentualne vrednosti harmonijskog izobličenja struje po fazama. Standardom IEC 61000-3-2 za ovaj potrošač se propisuje da je gornja granica $T H D I=58 \%$, na osnovu Tabele 6. može se zaključiti da faze 1. i 2. zadovoljavaju traženi standard dok faza 3. drastično prevazilazi standardnu vrednost.

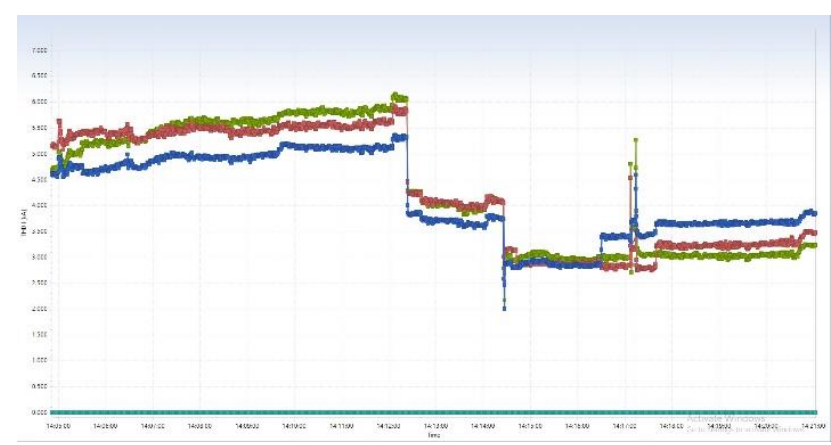

Slika 5. Totalno harmonijsko izobličenje struje I1, I2, I3
Tabela 4. Totalno harmonijsko izobličenje struje (\%)

\begin{tabular}{|c|c|c|}
\hline THDI1(\%) & THDI2(\%) & THDI3(\%) \\
\hline 29.45 & 47.35 & 93.34 \\
\hline 27.29 & 42.53 & 76.56 \\
\hline 25.87 & 39.62 & 66.28 \\
\hline 23.64 & 34.83 & 54.52 \\
\hline 26.53 & 41.18 & 70.48 \\
\hline 26.77 & 41.53 & 71.79 \\
\hline 26.31 & 40.77 & 70.82 \\
\hline 27.72 & 44.24 & 81.36 \\
\hline 27.69 & 44.05 & 79.55 \\
\hline 32.54 & 54.8 & 108.29 \\
\hline
\end{tabular}

\section{ZAKLJUČAK}

U ovom radu je dat teorijski i eksperimentalni prikaz kvaliteta električne energije. U eksperimentalnom delu dat je prikaz kvaliteta električne energije industrijskog potrošača na naftoj bušotini, grafički i brojčani prikaz najvažnijih vrednosti za ovaj potrošač : napon, struja, totalno harmonijskog izobličenje napona, totalno harmonijskog izobličenje struje, frekvencija $i$ flikeri. Pored ovih parametara ima jos dosta parametara koje uređaj Siemens SENTRON PAC3200 meri ali nisu od relevantnog značaja za ovaj eksperiment. Na osnovu prikazanih vrednosti dolazi se do zaključka da ovaj potrošač zadovoljava sve pomenute standarde $\mathrm{i}$ da su vrednosti u granicama normale sem u slučaju THDI3 gde su vrednosti iznad gornje granice koju zahteva standard. Razlog tome je što treća faza napaja najviše uređaja energetske elektronike koji unose smetnje koje se mogu primetiti po brojnim vrednostima THDI3.

\section{LITERATURA}

[1].V.Katic-A.Tokic-T.Konjic-Kvalitet električne energije-2007.

[2].Prasanna Mantravadi: ,Modeling, simulation and implementation of Li-Ion battery powered electric and plug-in hybrid vehicles", Phd thesis, University of Akron, Aug. 2014. - EFEKTI HAMORNIKA STRUJE I NAPON

[3].https://cache.industry.siemens.com/dl/files/150/26504 150/att_906558/v1/A5E01168664B-04_ENUS_122016_201612221316360495.pdf - SENTRON PAC3200

[4].https://matemamomenti.files.wordpress.com/2016/06/ nikola-mandic487-maturski-rad.pdf - furijeova transformacija

\section{Kratka biografija:}

Slobodan Milosavljević je rođen u Zrenjaninu 1994. god. Master rad na Fakultetu tehničkih nauka iz oblasti Elektrotehnike i računarstva - Energetska elektronika i električne mašine odbranio je 2021. god.. 